\title{
A roadmap towards the global view on vegetation
}

\author{
Norbert Jürgens (Chief Editor)
}

It is a pleasure to introduce this new volume of Biodiversity \& Ecology with the title Vegetation databases for the 21st century. This volume certainly forms an important contribution to the great endeavour to create the holistic view at the world's biodiversity. Vegetation databases carry information on both, the composition of the plant cover itself and on vegetation being an important component of ecosystems and both are directly related to environmental conditions. Therefore, vegetation databases will also be an important tool to assess change of vegetation and environment, in time.

In this sense, the present volume adds a most adequate new element to the journal Biodiversity \& Ecology and its general goal to contribute to an integrated view on the two major pillars of biodiversity: evolution and ecology. These three elements also underline the link to the Research Group Biodiversity, Evolution and Ecology of Plants (BEE) of the Biocentre Klein Flottbek, in its integration with the Herbarium Hamburgense and the Botanical Garden of the University of Hamburg.

At the same time, with this volume also the format of Biodiversity \& Ecology is progressing. An international team of editors coordinated the design of the volume, and all articles have been peer-reviewed, which will be standard for forthcoming volumes. Furthermore, free access online publication and assignment of DOIs (digital object identifiers) are newly introduced. Starting with the present Volume 4, Biodiversity \& Ecology will appear regularly with one volume per year. Special Volumes or Special Features will continue to play a key role in this journal, but also a limited number of regular submissions to the core focus will be possible in the future. To safeguard these developments and to manage the anticipated increased flow of manuscripts, Dr. Jens Oldeland (jens.oldeland@uni-hamburg.de) has been appointed as Managing Editor - he will support me and be responsible for the everyday business of the journal. In the near future, also an international board of Associate Editors will be installed to assist the Managing Editor and to oversee the peer review process. With all these changes in place, Biodiversity \& Ecology will apply for inclusion in the leading citation databases Web of Science and SCOPUS, which, if successful, will greatly contribute to the visibility and attractiveness of the journal.

I would finally like to take the opportunity to thank the guest editors from outside the Research Group BEE, Florian Jansen (Greifswald), Milan Chytrý (Brno, Czech Republic), Jörg Ewald (Freising), Falko Glöckler (Berlin), Gabriela LopezGonzalez (Leeds, United Kingdom), Robert K. Peet (Chapel Hill, NC, United States) and Joop H.J. Schaminée (Wageningen, Netherlands), who have invested a huge amount of time, energy and skills to produce this fine contribution.

Norbert Jürgens (norbert.juergens@uni-hamburg.de)

Biodiversity, Evolution and Ecology of Plants (BEE)

Biocentre Klein Flottbek and Botanical Garden

University of Hamburg

Ohnhorststr. 18

22609 Hamburg, GERMANY 
